\title{
Bdellovibrio bacteriovorus directly attacks Pseudomonas aeruginosa and Staphylococcus aureus Cystic fibrosis isolates
}

\author{
Valerio lebba ${ }^{1 * t}$, Valentina Totino ${ }^{1+}$, Floriana Santangelo ${ }^{1+}$, Antonella Gagliardi ${ }^{1}$, Luana Ciotoli ${ }^{1}$, \\ Alessandra Virga ${ }^{1}$, Cecilia Ambrosi ${ }^{1}$, Monica Pompili ${ }^{1}$, Riccardo V. De Biase ${ }^{2}$, Laura Selan ${ }^{1}$, \\ Marco Artini ${ }^{1}$, Fabrizio Pantanella ${ }^{1}$, Francesco Mura ${ }^{3}$, Claudio Passariello ${ }^{1}$, Mauro Nicoletti ${ }^{4}$, \\ Lucia Nencioni ${ }^{1}$, Maria Trancassini ${ }^{1+}$, Serena Quattrucci ${ }^{2+}$ and Serena Schippa ${ }^{1+}$ \\ 1 Microbiology Section, Department of Public Health and Infectious Diseases, "Sapienza" University, Rome, Italy \\ 2 Department of Pediatrics and Neuropsychiatry, "Sapienza" University, Rome, Italy \\ 3 Sapienza Nanoscience and Nanotecnology Laboratories, Department of Fundamental and Applied Sciences for Engineering, "Sapienza" University, Rome, Italy \\ ${ }^{4}$ Section of Microbiology, Department of Biomedical Sciences, University G. D'Annunzio, Chieti, Italy
}

\section{Edited by:}

Evangelos Giamarellos-Bourboulis, University of Athens, Greece

Reviewed by:

Mattias Collin, Lund University, Sweden

George Dimopoulos, University Hospital Attikon, Greece

*Correspondence:

Valerio lebba, Microbiology Section, Department of Public Health and Infectious Diseases, "Sapienza" University of Rome, Piazzale Aldo Moro, 500185 Rome, Italy e-mail: valerio.iebba@uniroma1.it

tThese authors have contributed equally to this work.
Bdellovibrio bacteriovorus is a predator bacterial species found in the environment and within the human gut, able to attack Gram-negative prey. Cystic fibrosis (CF) is a genetic disease which usually presents lung colonization by Pseudomonas aeruginosa or Staphylococcus aureus biofilms. Here, we investigated the predatory behavior of $B$. bacteriovorus against these two pathogenic species with: (1) broth culture; (2) "static" biofilms; (3) field emission scanning electron microscope (FESEM); (4) "flow" biofilms; (5) zymographic technique. We had the first evidence of B. bacteriovorus survival with a Gram-positive prey, revealing a direct cell-to-cell contact with $S$. aureus and a new "epibiotic" foraging strategy imaged with FESEM. Mean attaching time of HD100 to $S$. aureus cells was $185 \mathrm{~s}$, while "static" and "flow" S. aureus biofilms were reduced by 74 (at $24 \mathrm{~h}$ ) and $46 \%$ (at $20 \mathrm{~h}$ ), respectively. Furthermore, zymograms showed a differential bacteriolytic activity exerted by the $B$. bacteriovorus lysates on $P$. aeruginosa and $S$. aureus. The dual foraging system against Gram-negative (periplasmic) and Gram-positive (epibiotic) prey could suggest the use of $B$. bacteriovorus as a "living antibiotic" in CF, even if further studies are required to simulate its in vivo predatory behavior.

Keywords: Bdellovibrio bacteriovorus, Staphylococcus aureus, Pseudomonas aeruginosa, biofilm, predation, Cystic fibrosis, FESEM

\section{INTRODUCTION}

Cystic Fibrosis is a lethal genetic disease (Davis et al., 1996; Lyczak et al., 2002) in which mutations in the CF transmembrane Conductance Regulator (CFTR) gene result in defective function and/or processing of the mutant protein CFTR (Zielenski and Tsui, 1995; Gadsby et al., 2006). Patients are prone to chronic, persistent, and recurrent respiratory tract infections, with an exaggerated inflammatory response, leading to progressive respiratory deficiency (Boucher, 2002; Dakin et al., 2002; Rajan and Saiman, 2002). Even if the lung is usually inhabited by various bacterial species (Goddard et al., 2012), in CF disease only one or two pathogenic species prevail (Moore et al., 2005; Harrison, 2007; Sibley and Surette, 2011), usually the Gram-negative $P$. aeruginosa and the Gram-positive S. aureus. These two species are able to establish chronic infections through biofilm formation and resistance, leading to clinical exacerbations (Lyczak et al., 2002; Rajan and Saiman, 2002). Due to the polymicrobial nature of healthy lung microbiota and, conversely, to the predominance of only one/two pathogenic species in CF (Moore et al., 2005), it was suggested how manipulating lung communities would be effective against chronic infections (Harrison, 2007). From literature it was reported that a bacterial predator, Bdellovibrio bacteriovorus, is capable to attack different Gram-negative bacterial genera (Escherichia, Salmonella, Legionella, Pseudomonas) and their pre-formed biofilms (Sockett and Lambert, 2004; Kadouri and O'Toole, 2005). B. bacteriovorus is ubiquitous in the environment, where it's alleged to act as an "ecological balancer species" (Varon, 1981; Yair et al., 2003; Dwidar et al., 2012), and it was recently found in the human gut of all healthy individuals examined (Iebba et al., 2013). B. bacteriovorus has the natural ability to predate Gram-negative bacteria by invading their periplasmic space, where it undergoes a complex replication cycle culminating in prey killing and release of progeny (Rendulic et al., 2004; Lambert et al., 2006). Lytic action exerted by $B$. bacteriovorus can rapidly reduce prey populations, making this predatory species, or its lytic enzymes (Dori-Bachash et al., 2008; Lambert et al., 2010; Lerner et al., 2012), potential therapeutic candidates (Sockett and Lambert, 2004; Dwidar et al., 2012). Research is still necessary to give insights into the predatory spectrum of Bdellovibrio. The present study aimed at evaluating the predatory activity of $B$. bacteriovorus strain HD100 on bacterial strains commonly isolated from CF patients, such as the Gram-negative P. aeruginosa and the Gram-positive S. aureus. 


\section{MATERIALS AND METHODS BACTERIAL STRAINS AND CULTIVATION}

The predator Bdellovibrio bacteriovorus strain HD100 (DSM No. 50701), was acquired by the German microorganisms collection DSMZ (Braunschweig, Germany), and arrived in our lab in a "double-layer agar plate" containing diluted Nutrient-broth (NB) (1:10 dilution of $\mathrm{NB}$ amended with $3 \mathrm{mM} \mathrm{MgCl}_{2} \bullet 6 \mathrm{H}_{2} \mathrm{O}$ and $\left.2 \mathrm{mM} \mathrm{CaCl}_{2} \bullet 2 \mathrm{H}_{2} \mathrm{O}[\mathrm{pH} 7.2]\right)$ and agar (0.6\% upper layer) with enclosed prey cells of $P$. aeruginosa and B. bacteriovorus forming lysis plaque (Starr, 1975). Prey bacterial strains ( $P$. aeruginosa and $S$. aureus) used in this study were recovered from glycerol stocks stored at $-80^{\circ} \mathrm{C}$, and were previously collected from sputa of two Cystic fibrosis patients with chronic mono-colonization attending the Cystic fibrosis center of Lazio Region, "Sapienza" University of Rome. All strains were identified with the automated Vitek 2 system (Biomèrieux, Marcy l'Etoile, France). Strains were first suspended in Tryptone Soya Broth (TSB), and, to verify the purity of the culture, $100 \mu \mathrm{L}$ of overnight culture were spread onto Tryptone Soya Agar (TSA) plates. Vitek2 assessed strain identification again. The predator strain $B$. bacteriovorus was grown as previously reported (Kadouri and O'Toole, 2005; Jurkevitch, 2006; Lambert and Sockett, 2008) in DNB minimal medium. Briefly, DNB growth medium contained: $0.8 \mathrm{~g} / \mathrm{L}$ Bacto Nutrient Broth $(\mathrm{NB})$ and $0.1 \mathrm{~g} / \mathrm{L}$ yeast extract, with the separated addition of $0.45 \mu \mathrm{m}$-filtered $0.3 \mathrm{~g} / \mathrm{L}$ of Casaminoacids, $0.5 \mathrm{~g} / \mathrm{L}$ of $\mathrm{CaCl}_{2} \times$ $2 \mathrm{H}_{2} \mathrm{O}$ and $0.6 \mathrm{~g} / \mathrm{L}$ of $\mathrm{MgCl}_{2} \times 6 \mathrm{H}_{2} \mathrm{O}$. To obtain an enriched predator preparation to be used in predation assays, we modified the cultivation media doubling the concentration of NB from 0.8 to $1.6 \mathrm{~g} / \mathrm{L}$, and the resulting medium was hereafter named " $2 \mathrm{X}$ DNB."

\section{PREPARATION OF B. BACTERIOVORUS SUSPENSION FOR PREDATORY ASSAYS}

Two small pieces of agar were removed from a commercially available "double-layer agar plate" of B. bacteriovorus preying on $P$. aeruginosa, as recommended by DSMZ instructions, and added to $60 \mathrm{~mL}$ of " $2 \mathrm{X}$ DNB." Incubation was performed at $30^{\circ} \mathrm{C}$ under agitation ( $180 \mathrm{rpm})$ for $48 \mathrm{~h}$. Through microscopic observations at $100 \mathrm{X}$ magnification and the hanging drop technique, we were able to follow and measure every $2 \mathrm{~h}$ the growth of $B$. bacteriovorus, discernible by a reduction in $\mathrm{OD}_{600}$ turbidity (clear lysate). Upon reaching $48 \mathrm{~h}, 30 \mathrm{~mL}$ of the clear lysate were $0.45 \mu \mathrm{m}$-filtered for three times in order to remove prey cells. One-hundred $\mu \mathrm{L}$ of the filtrate were plated on TSA agar plates, and incubated at $37^{\circ} \mathrm{C}$ overnight to exclude carryover of the prey ( $P$. aeruginosa). Finally, to have a three-times concentrated suspension of $B$. bacteriovorus and to remove the " $2 \mathrm{X}$ DNB" broth, which initial tests showed to interfere with prey biofilm (data not shown), the $0.45 \mu \mathrm{m}$ filtrate was centrifuged at $10,000 \mathrm{~g}$ for $30 \mathrm{~min}$ and pellet was suspended in $10 \mathrm{~mL}$ of TSB. B. bacteriovorus suspension was prepared fresh each time for subsequent experiments.

\section{PREDATION ASSAYS ON PREY CULTURES}

One colony of prey ( $P$. aeruginosa or $S$. aureus) was picked up from TSA plates and grown overnight in $20 \mathrm{~mL}$ of TSB at $37^{\circ} \mathrm{C}, 200 \mathrm{rpm}$. Bacterial culture was centrifuged $(5000 \mathrm{~g}$, $15 \mathrm{~min}$ ) and pellet suspended in pre-warmed TSB till reaching an $\mathrm{OD}_{600}=1$. One-hundred $\mu \mathrm{L}$ of suspended culture were used to inoculate $60 \mathrm{~mL}$ of pre-warmed TSB, and incubated at $30^{\circ} \mathrm{C}$ with shaking $(200 \mathrm{rpm})$. Bacterial growth was followed each hour with a spectrophotometer (BioPhotometer, Eppendorf, Hamburg, Germany), and at $\mathrm{OD}_{600}=1$ the prey culture was split into three different $100 \mathrm{~mL}$-flasks at equal volumes $(20 \mathrm{~mL}):(1)$ the first left as it is; (2) the second added with $2 \mathrm{~mL}$ of $B$. bacteriovorus suspension (see "B. bacteriovorus suspension for predatory assays" paragraph); (3) the third added with $2 \mathrm{~mL}$ of B. bacteriovorus suspension $0.22 \mu \mathrm{m}$-filtered (for assessing the action of lytic enzymes eventually released into the medium). Flasks were incubated at $30^{\circ} \mathrm{C}$ with shaking $(200 \mathrm{rpm})$ into the same incubator/shaker GFL 3031 (MicroGlass Heim, Naples, Italy) and bacterial growth was measured every hour in two different ways: (1) $\mathrm{OD}_{600}$ (BioPhotometer, Eppendorf, Hamburg, Germany); (2) bright field through the "hanging drop" technique (optical microscope DM 5000-D, Leica Microsystems, Wetzlar, Germany). Prey levels ( $P$. aeruginosa and $S$. aureus) were assessed plating every $2 \mathrm{~h}$, on TSA plates, $100 \mu \mathrm{L}$ taken from the abovementioned first and second flasks, along with appropriate serial dilutions: colonies formed on plates after $17 \mathrm{~h}$ at $37^{\circ} \mathrm{C}$ were automatically counted by means of the TotalLab TL120 software (Non-linear Dynamics), "colony counting" module. Predation assays in TSB broth were performed in triplicate: $\mathrm{OD}_{600}$ values and colony forming units (CFU) per $\mathrm{mL}$ were expressed as mean $\pm \mathrm{SD}$ of the mean. Graphs and statistical tests were done with Prism 5 software (GraphPad, La Jolla, California, USA).

\section{PREDATORY ACTIVITY OF B. BACTERIOVORUS ON "STATIC" BIOFILMS}

Biofilms of $P$. aeruginosa and $S$. aureus were pre-formed on 48well plates as already reported (Merritt et al., 2005). Briefly, $200 \mu \mathrm{L}$ of prey overnight cultures diluted in $\mathrm{TSB}$ at $\mathrm{OD}_{600}=1$ were used to inoculate the 48 -well plate, followed by incubation at $37^{\circ} \mathrm{C}$ for $24 \mathrm{~h}$. Planktonic bacteria were removed by Phosphate Buffered Saline (PBS) washing. After washing, $200 \mu \mathrm{L}$ of B. bacteriovorus preparation (see "Preparation of $B$. bacteriovorus for predatory assays" paragraph) were added to $1 / 2$ plate, while $1 / 4$ was added with $200 \mu \mathrm{L}$ of $0.22 \mu \mathrm{m}$-filtered B. bacteriovorus preparation, and another $1 / 4$ was added with $200 \mu \mathrm{L}$ of TSB (control). Plates were incubated at $37^{\circ} \mathrm{C}$ for additional $24 \mathrm{~h}$ to allow B. bacteriovorus predation against prey biofilm. Then, all wells were washed with PBS for three times, then $100 \mu \mathrm{L}$ of $1 \%$ crystal violet were added to each well and left in contact for $5 \mathrm{~min}$. The dye in excess was eliminated by three washes with PBS, and the plate dried in a thermostat. $250 \mu \mathrm{L}$ of $33 \%$ glacial acetic acid were added to each well and left in contact for $15 \mathrm{~min}$. Subsequent $\mathrm{OD}_{570}$ readings were done with $\mathrm{VMax}^{\circledR}$ Kinetic Microplate Reader (Molecular Devices, Sunnyvale, CA, USA). Wilcoxon Signed Rank test was employed to assess differences in biofilm amount, and a $P$-value less than or equal to 0.05 was considered statistically significant. Graphs and statistical tests were done with Prism 5 software (GraphPad, La Jolla, California, USA).

\section{FIELD-EMISSION SCANNING ELECTRON MICROSCOPY (FESEM) OF $S$.} AUREUS BIOFILMS

FESEM technique was employed to visualize $S$. aureus biofilm before and after a $24 \mathrm{~h}$-challenge of B. bacteriovorus. As a substrate for FESEM microscopy, double-sided polished silicon wafers were 
reduced into many thin pieces by using a diamond cutter along natural crystallographic lines. Pieces of silicon wafers (hereafter mentioned as "wafers") were sterilized at $121^{\circ} \mathrm{C}$ for $15 \mathrm{~min}$ and then aseptically used as a substrate for bacterial biofilm growth. Wafers were separately immersed in $5 \mathrm{~mL}$ of $10^{6} \mathrm{CFU} / \mathrm{mL}$ of $P$. aeruginosa or $S$. aureus broth cultures, respectively. After $24 \mathrm{~h}$ of incubation at $37^{\circ} \mathrm{C}, 180 \mathrm{rpm}$, the supernatant and the planktonic preys were gently removed and replaced by $B$. bacteriovorus suspension (see "B. bacteriovorus suspension for predatory assays" paragraph). The predator was left in presence of the different prey-biofilms for additional $24 \mathrm{~h}$. After $24 \mathrm{~h}$ of contact between predator and preys, all wafers were gently rinsed by sterile saline solution (PBS) and immediately immersed in a fixative solution consisting of glutaraldehyde and PBS $(2 \% \mathrm{v} / \mathrm{v})$. At this step, all samples were maintained in the dark at $25^{\circ} \mathrm{C}$ for $1 \mathrm{~h}$, then washed three times in PBS and immediately after immersed in osmium tetroxide 1\% aqueous solution (cat\# 75632-10 ML, Sigma-Aldrich, St. Louis, MO, USA) and kept in the dark for $24 \mathrm{~h}$ at $4^{\circ} \mathrm{C}$. To obtain the necessary dehydration, after three PBS washes, wafers were immersed for $10 \mathrm{~min}$ each time in subsequent ethanol solutions increasing progressively in concentration from 30 to $99 \%$ (30-50-70-80-90-99\%). After drying at room temperature, samples were observed by FESEM microscopy. Identical preparation procedure has been adopted for all the control samples without predator or prey. FESEM images were captured using a Zeiss Auriga 405 (Carl Zeiss AG, Oberkochen, Germany). Different extraction voltages (5-10 keV) and a specific working distance (around $4 \mathrm{~mm}$ ) were employed to find an affordable compromise among avoiding the radiation damage and enhancing the contrast between bacterial cells and siliceous substrate. FESEM images were captured without any additional surface coating of the sample, in order to evaluate the actual surface morphology of bacterial cells.

\section{PREDATORY ACTIVITY OF B. BACTERIOVORUS ON "FLOW" BIOFILMS}

BioFlux system (Fluxion Biosciences, South San Francisco, CA) was used to visualize and follow in a time-dependent manner the development and the subsequent predatory activity of $B$. bacteriovorus. Microfluidic plates used were BioFlux 200 WPM 24 well plates 0-20 Dynes (cat. \#910-0009), and instrumental setup was set following manufacturer's instructions and literature (Benoit et al., 2010). Two wells were inoculated with $800 \mu \mathrm{L}$ of a suspension of the bacterial prey ( $P$. aeruginosa or $S$. aureus) in TSB $\left(\mathrm{OD}_{600}=1\right)$, to allow biofilm formation within each microfluidic channel. An initial pressure of $2 \mathrm{dyne} / \mathrm{cm}^{2}$ for $4 \mathrm{~s}$ was applied in the upper side of the inlet allowing the initial flow of bacterial inoculum. Flow was then stopped for $30 \mathrm{~min}$ to allow the initial stages of biofilm formation, then $2 \mathrm{~mL}$ of pre-warmed TSB medium were added, and flow started again at 0.5 dyne $/ \mathrm{cm}^{2}$, $37^{\circ} \mathrm{C}$ for $24 \mathrm{~h}$. Pre-formed biofilm was then added with $2 \mathrm{~mL}$ of $B$. bacteriovorus preparation (upper channel), while the control microfluidic well (lower channel) was added with $2 \mathrm{~mL}$ of TSB. When the B. bacteriovorus preparation and TSB were added, the flow was started again at $0.5 \mathrm{dyne} / \mathrm{cm}^{2}, 37^{\circ} \mathrm{C}$ for $24 \mathrm{~h}$. Still frames were taken every minute during the entire procedure (biofilm formation, predation) with a QICAM 12-bit camera (QImaging, Surrey, Canada) at a resolution of $1392 \times 1040$ pixels $(4.65 \times$
$4.65 \mu \mathrm{m}$ pixel size) and 12-bit of image depth. By means of a specific software (ImageJ, National Institutes of Health, USA), measurements of gray intensity were made for each frame in a $0-255$ scale, where 0 is black and 255 is white. Due to the different bacterial cell sizes of $P$. aeruginosa (rod-shaped, mean length and width, 3.0 and $0.8 \mu \mathrm{m}$, respectively), S. aureus (spherical, mean diameter $1.0 \mu \mathrm{m}$ ), and B. bacteriovorus (rod-shaped, mean length and width, 1.2 and $0.4 \mu \mathrm{m}$, respectively), the gray intensity value given by $B$. bacteriovorus alone was resulted to be $240.7 \pm 1.8$ (with a component of around $4 \%$ on the total mean gray intensity), and such a value was subtracted from each frame. Experiments were performed in triplicate by the same operator, while gray intensity measures were done in triplicate on each still frame from three different operators. Wilcoxon Signed Rank test was employed to assess differences in mean gray intensity on each movie frame, and a $P$-value less than or equal to 0.05 was considered statistically significant. Graphs and statistical tests were done with Prism 5 software (GraphPad, La Jolla, California, USA).

\section{ZYMOGRAPHIC TECHNIOUE}

The zymographic is an electrophoretic technique which includes a substrate copolymerized in a polyacrylamide gel useful for the detection of enzyme activity. Zymographic technique included the use of fresh lysates of $B$. bacteriovorus loaded on polyacrylamide gel copolymerized with prey cells, and was used as stated in literature (Audy et al., 1989; Lantz and Ciborowski, 1994) with minor modifications. Briefly, polyacrylamide minigels contained $10 \%$ polyacrylamide, Tris- $\mathrm{HCl}$ ( $\mathrm{pH} 8.8$ ), sodiumdodecyl-sulphate (SDS) $0.1 \%$, and $15 \%$ of prey cell suspension at $\mathrm{OD}_{600}=20$. This huge bacterial density was necessary in order to hinder the action exerted by SDS, especially for $P$. aeruginosa. The B. bacteriovorus preparation was sonicated 10 times with a 300VT ultrasonic homogenizer (Biologics Inc., Manassas, Virginia, USA) to disrupt predator cells and bring enzymes in solution. Then, an equal volume of sample buffer (Bromophenol blue in $20 \%$ glycerol in 2:1 ratio) was added to the sonicated $B$. bacteriovorus, and loaded. The run was set with a constant voltage (120 volts for $1 \mathrm{~h}$ ). Renaturation of proteins in polyacrylamide gel was obtained by washing the gel for $3 \mathrm{~h}$, with changes of the solution every $30 \mathrm{~min}$, in renaturing buffer $(50 \mathrm{mM}$ Na-phosphate buffer at $\mathrm{pH} 7$ with $1 \%$ Triton X-100). After the $3 \mathrm{~h}$ of washings, the gel was left in renaturing buffer for additional $24 \mathrm{~h}$ at $37^{\circ} \mathrm{C}$. Gel was stained with $0.25 \%$ (w/w) Coomassie Brilliant Blue R250. Clear band on opalescent gel matrix indicated bacteriolytic activities. Zymograms were analyzed by TotalLab TL120 software (Non-linear Dynamics) and molecular weights of unknown lytic bands were inferred by a logarithmic interpolation of marker bands (unstained SDS-PAGE low range standard, Bio-Rad cat \#161-0304).

\section{RESULTS}

\section{B. BACTERIOVORUS HD100 PREDATION ON P. AERUGINOSA AND $S$. AUREUS IN BROTH CULTURE}

A first assessment of $B$. bacteriovorus predatory activity was done on prey species ( $P$. aeruginosa and $S$. aureus) in TSB broth. Predation curve of $B$. bacteriovorus on $P$. aeruginosa reached 
stabilization at $\mathrm{OD}_{600}=0.30$ (around $7.5 \times 10^{7} \mathrm{CFU} / \mathrm{mL}$ ) after $10 \mathrm{~h}$, and this turbidity level was stable till the end of assay (Figure 1A). Interestingly, we observed predation of B. bacteriovorus against the Gram-positive S. aureus (Figure 1B), and in this case the predation curve stabilized itself at $\mathrm{OD}_{600}=$ 0.38 (around $2.2 \times 10^{8} \mathrm{CFU} / \mathrm{mL}$ ) after $7 \mathrm{~h}$. A slight reduction in $\mathrm{OD}_{600}$ measurements was visible when $0.22 \mu \mathrm{m}$-filtered suspension of B. bacteriovorus was added to prey cultures, but this reduction was not significant in both prey species (data not shown). Due to the unexpected observation of $B$. bacteriovorus HD100 predation on S. aureus in broth culture, we decided to see its actual predatory behavior utilizing the "hanging drop" technique and making a movie with an optical microscope (bright field) at 100X magnification (Supplementary Video S1). In Figure 2 are reported eight frames from Movie S1 depicting four distinct phases of $B$. bacteriovorus predation on S. aureus: sensing (Figures 2A-C), attacking (Figures 2D,E), breaching (Figures $2 \mathrm{~F}-\mathbf{H}$ ), and detaching (Figures 2I,J). As shown in Supplemental Movie (Supplementary Video S1) and Figure 2, while B. bacteriovorus swims at high speed from a lower depth level (Figure 2A), it surpasses $S$. aureus cells (Figure 2B), swiftly turns back (Figures 2C,D), and hooks one of them (Figure 2E), exhibiting a bending of its cellular body (Figure 2E). After twisting for around $11 \mathrm{~s}$ trying to breach its prey (Figures $2 \mathrm{~F}-\mathrm{H}$ ), B. bacteriovorus detaches from Gram-positive prey cell (Figure 2I) and moves away (Figure 2J). Time spent by $B$. bacteriovorus during the breaching phase on S. aureus (from attacking till detaching) was computed for different predator/prey couples, and resulted to be $185.5 \pm 25.7 \mathrm{~s}$ (mean $\pm \mathrm{SD}$ of the mean). Interestingly, predators who spent more time attached to $S$. aureus cells trying to breach them, in most cases were steady, with no detectable twisting (Figure 2 and Supplementary Video S1, bright blue prey; Supplementary Video S2). Such an observation shows an unconventional predatory behavior of B. bacteriovorus HD100, which usually holds on in twisting upon attaching Gram-negative prey to breach and penetrate into periplasmic space (Medina et al., 2008). No bdelloplast formation was observed throughout the entire period of observation (12 h).

\section{B. BACTERIOVORUS HD100 REDUCES "STATIC" PREY BIOFILMS}

Twenty-four hours-old biofilms of $P$. aeruginosa and $S$. aureus strains were challenged for $24 \mathrm{~h}$ with B. bacteriovorus predation, and quantified by crystal violet staining followed by $\mathrm{OD}_{570}$ readings. $P$. aeruginosa biofilm was significantly reduced of $76 \%$, while S. aureus biofilm was reduced of $74 \%(P<0.0001$, Figure 3$)$. A prey preference of $B$. bacteriovorus for $P$. aeruginosa was visible, whose biofilm was reduced $9.3 \%$ more than $S$. aureus $(P=$ 0.0437) (Figure 3). Even if significantly different, the similar biofilm amount of the two challenged species could indicate a similar predatory level exerted by B. bacteriovorus, irrespective from presence or absence of periplasmic replication. Biofilm amount in both prey species was not significantly affected by $0.22 \mu \mathrm{m}$-filtered suspension of B. bacteriovorus HD100, in which lytic enzymes would be eventually released $(P$. aeruginosa, $P=$ 0.8667 ; S. aureus, $P=0.8596$ ), signifying that a specific predatorprey interaction is needed to challenge pre-formed biofilms.

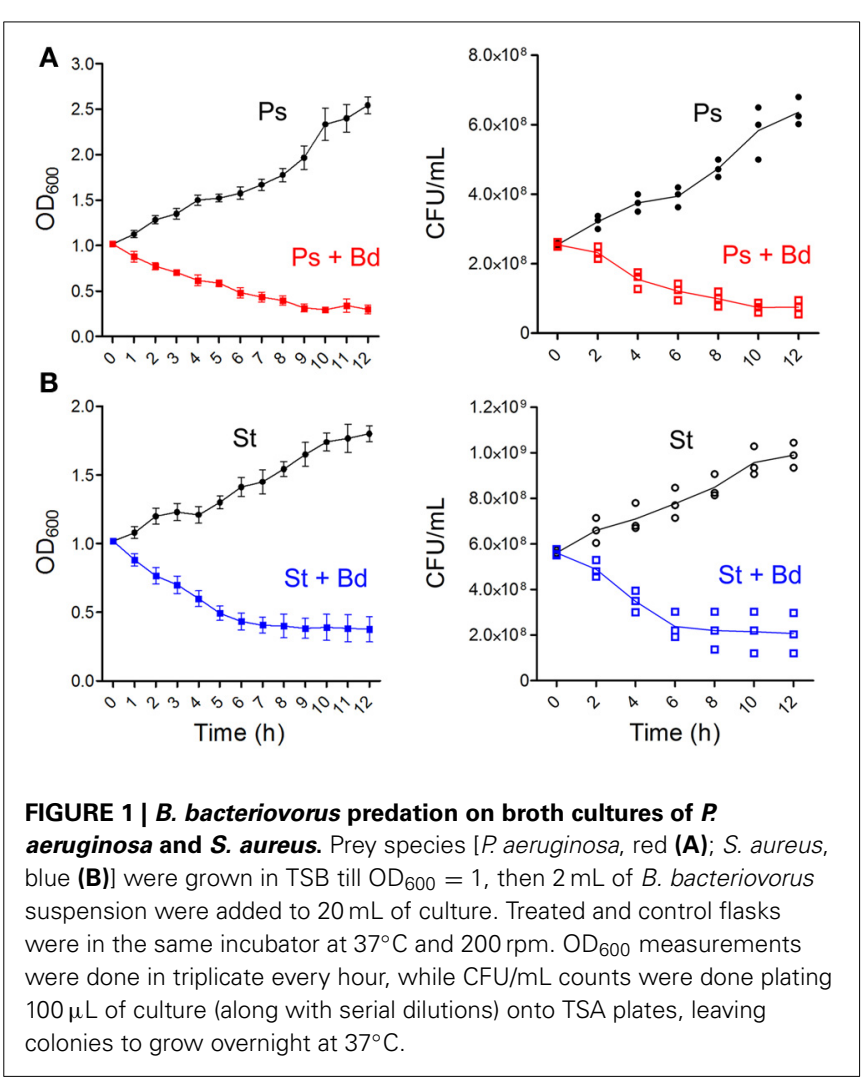

\section{B. BACTERIOVORUS HD100 SHOWS AN EPIBIOTIC PREDATION ON $S$. AUREUS}

Results obtained with "hanging drop" technique (Figure 2, Supplementary Video S1, Supplementary Video S2) allowed us to see the predatory behavior of HD100 toward S. aureus, thus, the subsequent step was to find out a better visualization of $B$. bacteriovorus attacking its Gram-positive prey. To this end, we employed FESEM technique on pre-formed biofilm of $S$. aureus before and after a challenge with $B$. bacteriovorus. Biofilm of $S$. aureus was grown on a siliceous slice for $24 \mathrm{~h}$ in TSB, then the medium was carefully removed and replaced with $5 \mathrm{~mL}$ of HD100 suspension (see "Preparation of B. bacteriovorus suspension for predatory assays") allowing biofilm challenge for another $24 \mathrm{~h}$. In Figure 4 are shown the results. A $24 \mathrm{~h}$-old S. aureus biofilm was established (Figure 4A), but after $24 \mathrm{~h}$ the biofilm was thoroughly removed, leaving few prey cells alive surrounded by many debris (Figure 4B) with a single B. bacteriovorus approaching through the long $(4 \mu \mathrm{m})$ flagellum (Figure 4B, inset). A higher FESEM magnification showed two B. bacteriovorus predators attacking two different $S$. aureus cells in an epibiotic manner, in which a direct contact (Figure 4C, white arrows) with prey cell is maintained throughout the entire predation process, from the initial attack phase (Figure 4C, left) till the late attack phase (Figure 4C, right). Interestingly, B. bacteriovorus HD100 was able to attack its prey with the anterior part, leaving the flagellum free to move, maybe aiding in pushing the predator body (Figures 2, 4C). This new behavior (epibiotic predation) against $S$. aureus is significantly different from what usually B. bacteriovorus HD100 does against Gram-negative prey (periplasmic predation). 


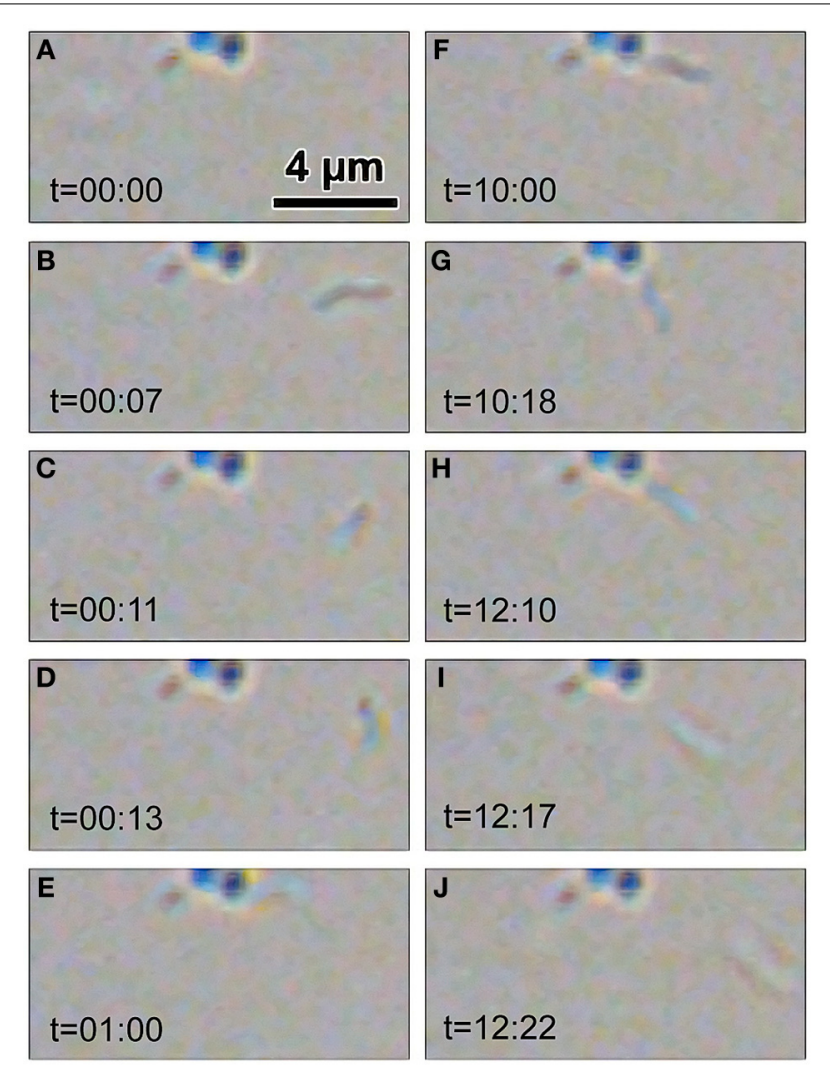

FIGURE 2 | B. bacteriovorus predation on two $\boldsymbol{S}$. aureus prey cells. Frames (A-J) from Supplementary Video S1 (bright field, 100X magnification) depicting predation phases of $B$. bacteriovorus on two $S$. aureus cells. Time $(t)$ is expressed as "seconds:frames," where each second is made of 25 frames. A single $B$. bacteriovorus enters from the left, attacks its prey (right, dark blue) and after around $12 \mathrm{~s}$ moves away. A second $B$. bacteriovorus is already attached to its prey (left, bright blue), perpendicularly to the frame level during the entire Supplementary Video S1.

\section{B. BACTERIOVORUS HD100 REDUCES "FLOW" PREY BIOFILMS}

CF patients' lungs show a somewhat impaired mucociliary clearance (MCC), even if precise in vivo measurements lead to controversial results depending on upper/lower lobes involvement (Tarran et al., 2005): such a diminished MCC allows bacterial establishment and permanence in biofilms (Mall et al., 2004; Donaldson et al., 2007). We then hypothesized that a physiologic shear-stress of $0.5 \mathrm{dyne} / \mathrm{cm}^{2}$, as found in periciliary liquid (PCL) of healthy and CF individuals (Regnis et al., 1994; McShane et al., 2004; Tarran et al., 2005), could affect B. bacteriovorus predation of prey biofilms. To test such hypothesis, evaluation of $B$. bacteriovorus predatory activity on preformed biofilms was done in dynamic settings, by means of BioFlux microfluidics apparatus. The first significant reduction of $P$. aeruginosa biofilm $(-31 \%)$ was visible after $9 \mathrm{~h}$ upon $B$. bacteriovorus challenge $(P=0.0175)$, while after $20 \mathrm{~h}$ it was reduced by $38 \%$ (Figure 5A). Interestingly, after a fixed decreasing rate (from 6 to $11 \mathrm{~h}$ ) of $P$. aeruginosa biofilm amount $(-6.3 \% / \mathrm{h})$, an oscillation with a period $\mathrm{T}_{P_{s}}=$ $4 \mathrm{~h}$ was visible starting around at $12 \mathrm{~h}$, reminiscent the predator/prey Lotka-Volterra model (Varon and Zeigler, 1978). Such

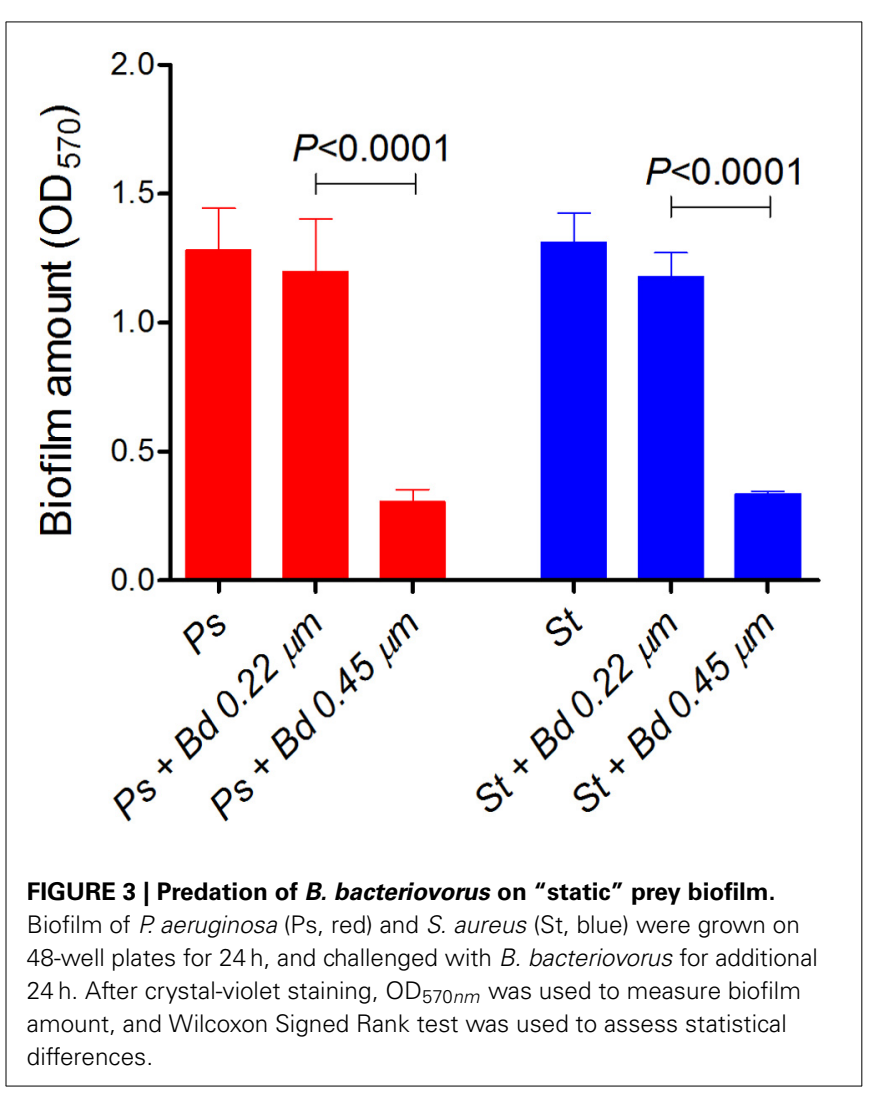

an oscillation was not due to the BioFlux peristaltic pump, which showed instead a period $\mathrm{T}_{\text {pump }}=0.7 \mathrm{~h}$. A significant reduction of S. aureus biofilm $(-33 \%)$ was visible after $14 \mathrm{~h}$ of contact with the predator $(P=0.0380)$, and after $20 \mathrm{~h}$ it was reduced by $46 \%$ (Figure 5B). From 6 to $8.5 \mathrm{~h}$ a fixed decreasing rate of $S$. aureus biofilm amount $(-17.5 \% / \mathrm{h})$ was observed, but no oscillations were visible thereafter, maybe owing to the absence of a host-dependent replicative cycle of $B$. bacteriovorus. Strikingly, as observed in static conditions, after $20 \mathrm{~h}$ of predation in flow settings both biofilm amounts reached a similar level of gray density $(169.1 \pm 18.0$ for $P$. aeruginosa, $170.2 \pm 7.4$ for $S$. aureus, Figure 5), with no significant difference $(P=0.9269)$.

\section{B. BACTERIOVORUS HD100 USES DIFFERENT NON-RELEASED DEGRADATIVE ENZYMES TO LYSE P. AERUGINOSA AND S. AUREUS}

Results obtained with the "hanging drop" technique (Figure 2, Supplementary Video S1, Supplementary Video S2), "static" biofilms (Figure 3), and FESEM images (Figure 4), suggested that a direct interaction of $B$. bacteriovorus $\mathrm{HD} 100$ is needed to ensure predation, and that its degradative enzymes eventually released into the medium do not exert a role in lysing neither free prey nor their pre-formed biofilms. Zymographic technique was used to find non-released bacteriolytic enzymes of $B$. bacteriovorus against cellular substrates of $S$. aureus or $P$. aeruginosa. Zymograms densitometry profiles were divided in 312 pixels and molecular weights of lytic bands (expressed as $\mathrm{kDa}$ ) were inferred by a logarithmic interpolation of the marker (Log curve, $y=111.6 e^{-0.009371 x}+14.66, R^{2}=1$ ). A differential 


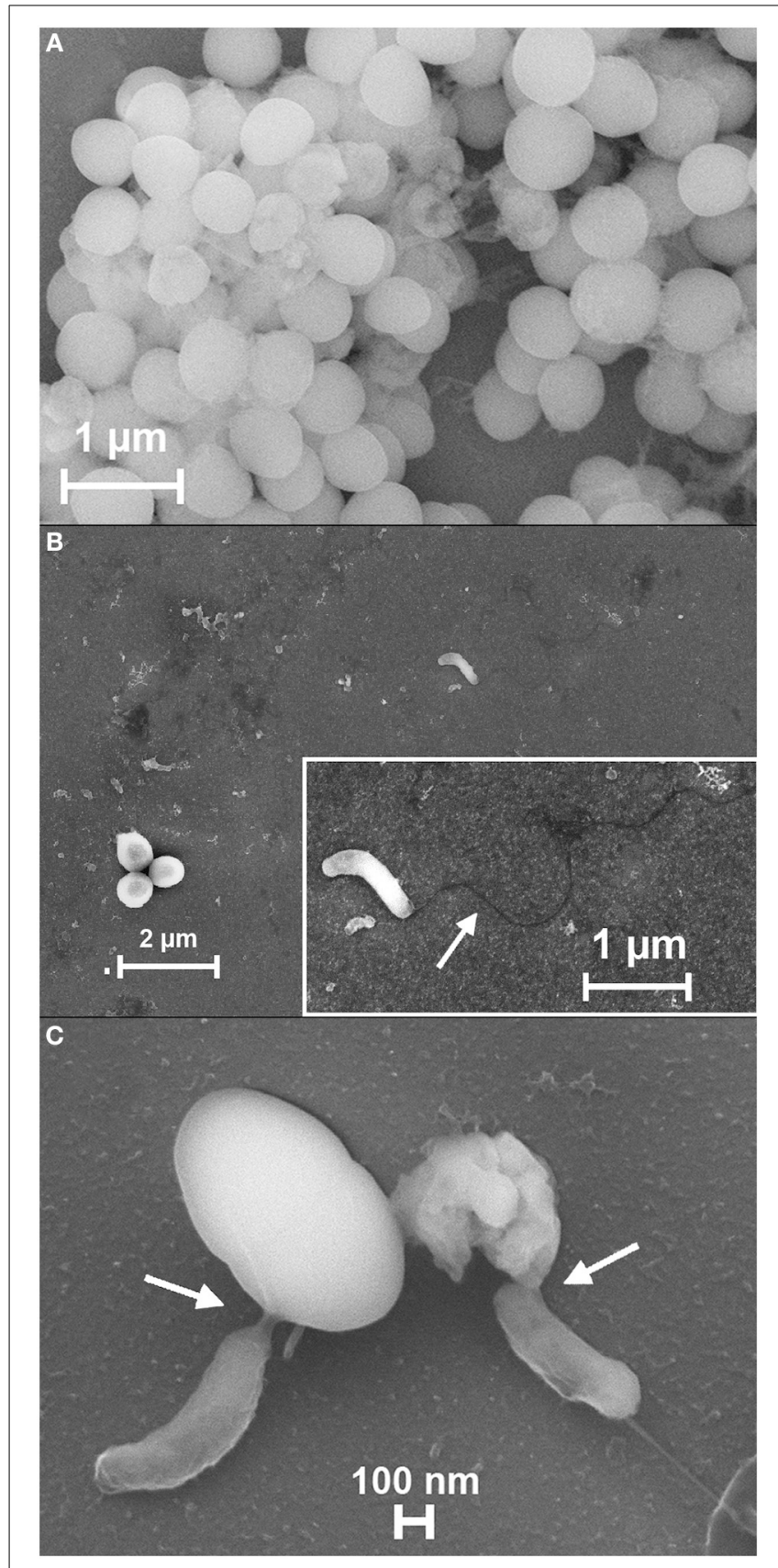

FIGURE 4 | Predation of $\boldsymbol{B}$. bacteriovorus on "static" biofilm of $\boldsymbol{S}$. aureus. s.e.m. images of $S$. aureus biofilm (A, 30000X) grown for $24 \mathrm{~h}$ on a silicon plate, and after $24 \mathrm{~h}$ of $B$. bacteriovorus HD100 predation (B, 20000X). A free Bdellovibrio is visible with its long polar flagellum (estimated length, $4 \mu \mathrm{m}$ ) (arrow, B, inset, 50000X). A higher s.e.m. magnification (88830X) shows the initial attack phase of HD100 on a prey cell (C, left) and the late attack phase, with a destroyed $S$. aureus cell (C, right). White arrows in (C) show the direct interaction of $B$. bacteriovorus HD100 with S. aureus.

bacteriolytic activity against $P$. aeruginosa and $S$. aureus was observed (Figure 6), with a unique clear band at around $22 \mathrm{kDa}$ for the Gram-negative prey, and three different lytic bands at 22, 44 , and $67 \mathrm{kDa}$ for the Gram-positive prey (Figure 6). SDS added

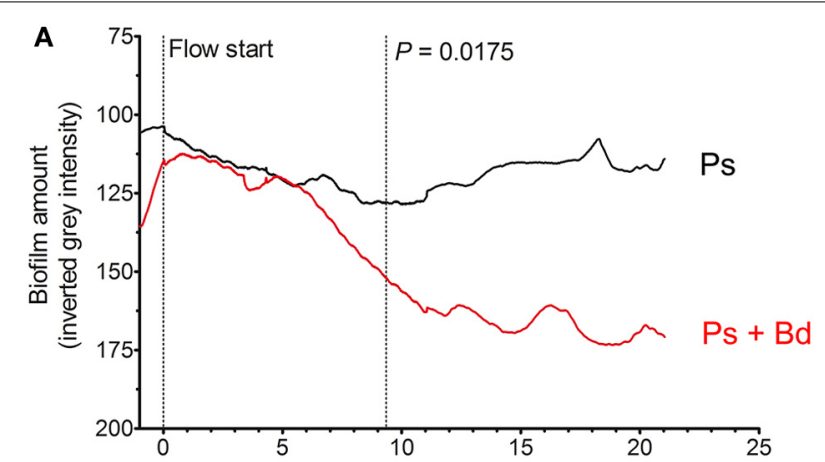

B

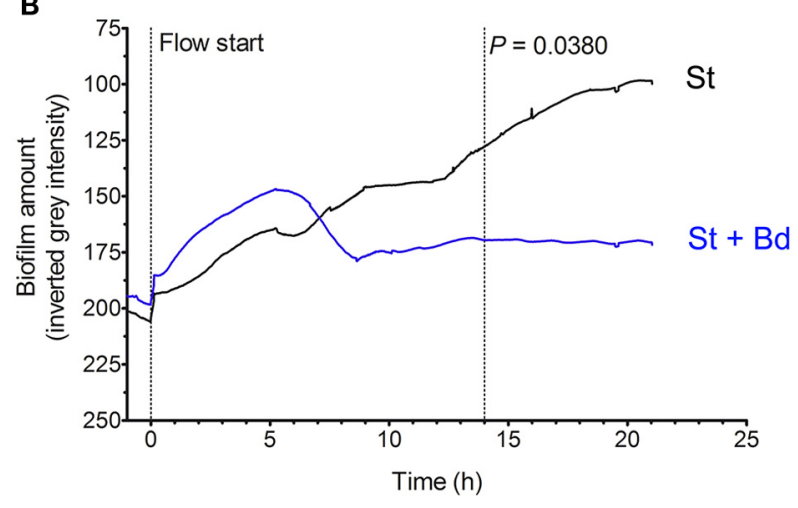

FIGURE 5 | Predation of $B$. bacteriovorus on "flow" prey biofilm.

Biofilms of $P$. aeruginosa (A, red) and $S$. aureus (B, blue) were grown in 24-well microfluidic plates (BioFlux), then challenged with $B$. bacteriovorus suspension for $24 \mathrm{~h}$. Biofilm amount was expressed as mean gray intensity (from 255-white to 0-black) of each movie frame, and statistical differences were assessed by Wilcoxon Signed Rank test.

to polyacrylamide gels allowed us to be quite confident in assessing the molecular weights of lytic bands (Lantz and Ciborowski, 1994), especially for S. aureus, even if a proper characterization of enzymes involved will be done in forthcoming experiments.

\section{DISCUSSION}

Since its discovery in 1963 (Stolp and Starr, 1963), Bdellovibrio was recognized as a predator species capable to prey Gramnegative bacteria, maybe exerting a role in regulating microbial communities (Varon, 1981; Yair et al., 2003; Dwidar et al., 2012). Previous reports suggested to use B. bacteriovorus, or similar predatory species, as a biological agent against bacterial pathogens, and found it to be actually useful in challenging such infections (Chu and Zhu, 2010; Atterbury et al., 2011; Dashiff and Kadouri, 2011; Dashiff et al., 2011). CF is usually accompanied to an exaggerated bacterial colonization of the lower respiratory tract (Moore et al., 2005; Harrison, 2007; Sibley and Surette, 2011), in which $P$. aeruginosa and S. aureus trigger an inflammatory response that leads to progressive clinical exacerbation (Lyczak et al., 2002; Rajan and Saiman, 2002). The objective of the present study was to evaluate the predatory activity of Bdellovibrio bacteriovorus strain HD100 against two bacterial pathogens usually isolated from CF patients' sputa, $P$. aeruginosa and $S$. aureus. To this end, the activity of $B$. bacteriovorus was evaluated vs. cells 


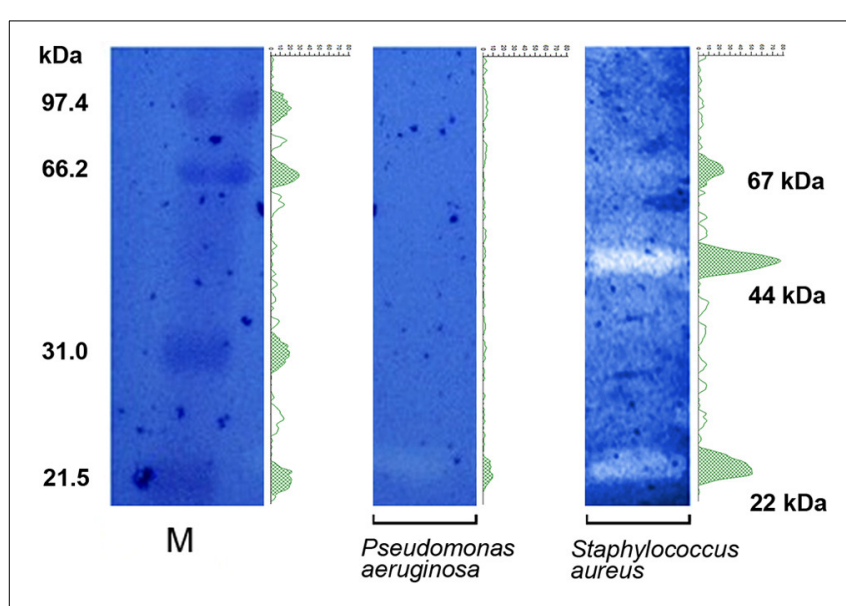

FIGURE 6 | Zymograms. P. aeruginosa e S. aureus were embedded into different polyacrylamide gels and wells were loaded with sonicated $B$. bacteriovorus. Species-specific lytic bands (white) were visible in correspondence of $B$. bacteriovorus-derived lytic enzymes, after blue coomassie staining. Densitometry profiles (green) were added to appreciate the differential bacteriolytic activity exerted by $B$. bacteriovorus on prey cells. $M$, marker (unstained SDS-PAGE low range standard, Bio-Rad cat \#161-0304).

prey in culture and on preformed biofilms, both in "static" and "flow" conditions. Bioflux results on P. aeruginosa revealed the instauration of a Lotka-Volterra predator/prey oscillation after $12 \mathrm{~h}$ of $B$. bacteriovorus attack: further experiments with fluorescent dyes will be addressed to ascertain the predator/prey ratio at the origin of this oscillation. Interestingly, the reduction rate of both Gram-negative and Gram-positive biofilms started at $6 \mathrm{~h}$ upon $B$. bacteriovorus challenge, and the final biofilm amount settled at around $-38 \%$ in both prey species (Figure 5). We cannot exclude that $S$. aureus biofilm was still growing while $P$. aeruginosa biofilm was at its plateau (Figure 5), but we found that such a biofilm development and subsequent predation was reproducible under simulated physiologic shear-stress ("flow" condition) of 0.5 dyne $/ \mathrm{cm}^{2}$ for both preys. "Flow" conditions diminished predatory activity of $B$. bacteriovorus by 38 (P. aeruginosa) and 28\% (S. aureus) compared to "static" conditions, and this observation could be useful if an in vivo treatment would be employed for B. bacteriovorus in CF disease. In this view, further studies are needed to validate the effect of shear-stress in PCL on $B$. bacteriovorus predation by using $\mathrm{CF}$ animal models.

We found that B. bacteriovorus strain HD100 could survive for a prolonged time (at least $20 \mathrm{~h}$ ) exclusively preying a Gram-positive species, here a $S$. aureus CF isolate. Previous papers reported how some bacterial predators genera, namely Cupriavidus (Casida, 1988), Lysobacter (Bonner et al., 1988), and Myxococcus (Shimkets, 1990), could prey Gram-positive preys in an epibiotic manner, but such an evidence was never reported for B. bacteriovorus species, nor Bdellovibrio genus, which instead requires an intra-periplasmic replication for its survival. Only a single study reported a similar epibiotic predation for a different Bdellovibrio strain, JSS, which is able to predate only the Gram-negative Caulobacter crescentus (Chanyi et al., 2013; Koval et al., 2013; Pasternak et al., 2014), and only another study used
Gram-positive species as decoys for B. bacteriovorus HD100 in a triple-planktonic predation system (Hobley et al., 2006). Unlike our results (Figure 3), a recent study reported how supernatant of a host-independent (HI) mutant of B. bacteriovorus HD100 is able to reduce $S$. aureus biofilm by $75 \%$, but predator itself is not able to do that (Monnappa et al., 2014). Monnappa and colleagues had this evidence on three different $S$. aureus strains, but no direct attack of $B$. bacteriovorus on $S$. aureus was visible. In our study, through FE-SEM, we had the first evidence of predation and survival of strain HD100 preying exclusively a Gram-positive species, with an attack-phase and an epibiotic predation (Figures 2, 4), leading to a diminution of $S$. aureus biofilm of $74 \%$ (Figure 3 ). Morphological changes in the predator/prey "region of contact" are currently under investigation, by means of transmission electron microscopy (TEM) and scanning-transmission electron microscopy (STEM) in our lab. Once depicted by TEM and STEM the intimate contact among $B$. bacteriovorus and $S$. aureus, the forthcoming step will be to study the underlying molecular mechanisms of $S$. aureus killing: due to the short mean predator/prey contact of $185 \mathrm{~s}$, it will be interesting to test if cell wall hydrolysis or protein synthesis interference, as previously observed for E. coli (Varon et al., 1969), could be responsible. One could also consider that $B$. bacteriovorus predation on $S$. aureus would be prey straindependent, or it would be different if an axenic $\mathrm{HI} B$. bacteriovorus is used (Monnappa et al., 2014). In our study we decided to see the actual predatory behavior of B. bacteriovorus strain HD100 against $S$. aureus, thus, an axenic HI variant was not used. We thus evidenced a specific interaction of HD100 with $S$. aureus cellular surface (Figure 4C, white arrows), in which the destruction of $S$. aureus cell seemed to occur through the rupture of its membrane and exudation of the cell content (Figure 4C). We also found that B. bacteriovorus HD100 was always attached epibiotically to $S$. aureus from the initial to the latter phase of prey destruction. It is conceivable that strain HD100 could use a specific repertoire of bacteriolytic enzymes to rupture $S$. aureus membrane to start exudation. Taking into account the $B$. bacteriovorus HD100 annotated genome (Rendulic et al., 2004), it is noteworthy how this strain owns a huge repertoire of hydrolytic enzymes, such as proteases, glycanases, and DNases. Interestingly, S. aureus zymogram showed three lytic bands, at 22, 44 and $67 \mathrm{kDa}$, among which the last two may represent an additional bacteriolytic activity compared to $P$. aeruginosa zymogram. Further studies are required to understand the mechanism of interaction among $B$. bacteriovorus and Gram-positive species, such as $S$. aureus, along with characterization of lytic enzymes involved and their mode of delivery.

Due to the spread of resistance among clinical pathogens, it was suggested how B. bacteriovorus could be used as a "living-antibiotic" (Rendulic et al., 2004; Sockett and Lambert, 2004). It is noteworthy that the dual foraging strategy exhibited by $B$. bacteriovorus on $S$. aureus (epibiotic) and $P$. aeruginosa (periplasmic), would be a favorable condition to actually significantly reduce bacterial loads and established biofilms both in mono- and bi-colonized CF patients, rather than disperse them. Dispersal of alive pathogen bacterial cells, as seen by using specific B. bacteriovorus-derived proteases (Monnappa et al., 2014), could be detrimental within an inflamed lung, leaving planktonic cells 
free to colonize other niches, thus exacerbating CF symptoms. $B$. bacteriovorus was found to be unable to infect mammalian cells (Sockett and Lambert, 2004), and was found in the healthy human gut (Iebba et al., 2013), making it a good candidate to treat infections in vivo, and results obtained in this study point toward its use in the treatment of CF pulmonary infections.

\section{AUTHOR CONTRIBUTIONS}

Valerio Iebba, Floriana Santangelo, Antonella Gagliardi, and Luana Ciotoli conceived and performed the experiments, Alessandra Virga, Cecilia Ambrosi, and Monica Pompili performed the zymographic experiments, Valentina Totino, Fabrizio Pantanella and Francesco Mura performed the FESEM imaging and analyses, Laura Selan and Marco Artini performed Bioflux experiments, Riccardo V. De Biase, Maria Trancassini, and Serena Quattrucci provided bacterial strains, Valerio Iebba, Claudio Passariello, Mauro Nicoletti, Lucia Nencioni., and Serena Schippa. wrote the main manuscript text and Valerio Iebba prepared the figures.

\section{ACKNOWLEDGMENTS}

This study was supported by Italian Foundation of Cystic Fibrosis, Grant FFC\#16/2011. Authors want to thank Dr. Andrea Cellini for his help with BioFlux experiments.

\section{SUPPLEMENTARY MATERIAL}

The Supplementary Material for this article can be found online at: http://www.frontiersin.org/journal/10.3389/fmicb. 2014.00280/abstract

\section{REFERENCES}

Atterbury, R. J., Hobley, L., Till, R., Lambert, C., Capeness, M. J., Lerner, T. R., et al. (2011). Effects of orally administered Bdellovibrio bacteriovorus on the wellbeing and Salmonella colonization of young chicks. Appl. Environ. Microbiol. 77, 5794-5803. doi: 10.1128/AEM.00426-11

Audy, P., Grenier, J., and Asselin, A. (1989). Lysozyme activity in animal extracts after sodium dodecyl sulfate-polyacrylamide gel electrophoresis. Comp. Biochem. Physiol. B 92, 523-527. doi: 10.1016/0305-0491(89)90126-0

Benoit, M. R., Conant, C. G., Ionescu-Zanetti, C., Schwartz, M., and Matin, A. (2010). New device for high-throughput viability screening of flow biofilms. Appl. Environ. Microbiol. 76, 4136-4142. doi: 10.1128/AEM.03065-09

Bonner, D. P., O’Sullivan, J., Tanaka, S. K., Clark, J. M., and Whitney, R. R. (1988). Lysobactin, a novel antibacterial agent produced by Lysobacter sp. II. Biological properties. J. Antibiot. 41, 1745-1751. doi: 10.7164/antibiotics.41.1745

Boucher, R. C. (2002). An overview of the pathogenesis of cystic fibrosis lung disease. Adv. Drug Deliv. Rev. 54, 1359-1371. doi: 10.1016/S0169-409X(02)00144-8

Casida, L. E. (1988). Response in soil of cupriavidus necator and other copperresistant bacterial predators of bacteria to addition of water, soluble nutrients, various bacterial species, or bacillus thuringiensis spores and crystals. Appl. Environ. Microbiol. 54, 2161-2166.

Chanyi, R. M., Ward, C., Pechey, A., and Koval, S. F. (2013). To invade or not to invade: two approaches to a prokaryotic predatory life cycle. Can. J. Microbiol. 59, 273-279. doi: 10.1139/cjm-2013-0041

Chu, W. H., and Zhu, W. (2010). Isolation of Bdellovibrio as biological therapeutic agents used for the treatment of Aeromonas hydrophila infection in fish. Zoonoses Public Health 57, 258-264. doi: 10.1111/j.1863-2378.2008.01224.x

Dakin, C. J., Numa, A. H., Wang, H., Morton, J. R., Vertzyas, C. C., and Henry, R. L. (2002). Inflammation, infection, and pulmonary function in infants and young children with cystic fibrosis. Am. J. Respir. Crit. Care Med. 165, 904-910. doi: 10.1164/ajrccm.165.7.2010139

Dashiff, A., Junka, R. A., Libera, M., and Kadouri, D. E. (2011). Predation of human pathogens by the predatory bacteria Micavibrio aeruginosavorus and
Bdellovibrio bacteriovorus. J. Appl. Microbiol. 110, 431-444. doi: 10.1111/j.13652672.2010.04900.x

Dashiff, A., and Kadouri, D. E. (2011). Predation of oral pathogens by Bdellovibrio bacteriovorus 109J. Mol. Oral Microbiol. 26, 19-34. doi: 10.1111/j.20411014.2010.00592.x

Davis, P. B., Drumm, M., and Konstan, M. W. (1996). Cystic fibrosis. Am. J. Respir. Crit. Care Med. 154, 1229-1256. doi: 10.1164/ajrccm.154.5. 8912731

Donaldson, S. H., Corcoran, T. E., Laube, B. L., and Bennett, W. D. (2007). Mucociliary clearance as an outcome measure for cystic fibrosis clinical research. Proc. Am. Thorac. Soc. 4, 399-405. doi: 10.1513/pats.200703-042BR

Dori-Bachash, M., Dassa, B., Pietrokovski, S., and Jurkevitch, E. (2008). Proteomebased comparative analyses of growth stages reveal new cell cycle-dependent functions in the predatory bacterium Bdellovibrio bacteriovorus. Appl. Environ. Microbiol. 74, 7152-7162. doi: 10.1128/AEM.01736-08

Dwidar, M., Monnappa, A. K., and Mitchell, R. J. (2012). The dual probiotic and antibiotic nature of Bdellovibrio bacteriovorus. BMB Rep. 45, 71-78. doi: 10.5483/BMBRep.2012.45.2.71

Gadsby, D. C., Vergani, P., and Csanady, L. (2006). The ABC protein turned chloride channel whose failure causes cystic fibrosis. Nature 440, 477-483. doi: 10.1038/nature04712

Goddard, A. F., Staudinger, B. J., Dowd, S. E., Joshi-Datar, A., Wolcott, R. D., Aitken, M. L., et al. (2012). Direct sampling of cystic fibrosis lungs indicates that DNAbased analyses of upper-airway specimens can misrepresent lung microbiota. Proc. Natl. Acad. Sci. U.S.A. 109, 13769-13774. doi: 10.1073/pnas.1107435109

Harrison, F. (2007). Microbial ecology of the cystic fibrosis lung. Microbiology 153, 917-923. doi: 10.1099/mic.0.2006/004077-0

Hobley, L., King, J. R., and Sockett, R. E. (2006). Bdellovibrio predation in the presence of decoys: three-way bacterial interactions revealed by mathematical and experimental analyses. Appl. Environ. Microbiol. 72, 6757-6765. doi: 10.1128/AEM.00844-06

Iebba, V., Santangelo, F., Totino, V., Nicoletti, M., Gagliardi, A., de Biase, R. V., et al. (2013). Higher prevalence and abundance of Bdellovibrio bacteriovorus in the human gut of healthy subjects. PLOS ONE 8:e61608. doi: 10.1371/journal.pone.0061608

Jurkevitch, E. (2006). Isolation and classification of bdellovibrio and like organisms. Curr. Protoc. Microbiol. Chapter 7: Unit 7B.1. doi: 10.1002/9780471729259.mc07b01s00

Kadouri, D., and O'Toole, G. A. (2005). Susceptibility of biofilms to Bdellovibrio bacteriovorus attack. Appl. Environ. Microbiol. 71, 4044-4051. doi: 10.1128/AEM.71.7.4044-4051.2005

Koval, S. F., Hynes, S. H., Flannagan, R. S., Pasternak, Z., Davidov, Y., and Jurkevitch, E. (2013). Bdellovibrio exovorus sp. nov., a novel predator of Caulobacter crescentus. Int. J. Syst. Evol. Microbiol. 63, 146-151. doi: 10.1099/ijs.0.039701-0

Lambert, C., Chang, C. Y., Capeness, M. J., and Sockett, R. E. (2010). The first biteprofiling the predatosome in the bacterial pathogen Bdellovibrio. PLoS ONE 5:e8599. doi: 10.1371/journal.pone.0008599

Lambert, C., Morehouse, K. A., Chang, C. Y., and Sockett, R. E. (2006). Bdellovibrio: growth and development during the predatory cycle. Curr. Opin. Microbiol. 9, 639-644. doi: 10.1016/j.mib.2006.10.002

Lambert, C., and Sockett, R. E. (2008). Laboratory maintenance of Bdellovibrio. Curr. Protoc. Microbiol. Chapter 7: Unit 7B.2. doi: 10.1002/9780471729259.mc07b02s9

Lantz, M. S., and Ciborowski, P. (1994). Zymographic techniques for detection and characterization of microbial proteases. Methods Enzymol. 235, 563-594. doi: 10.1016/0076-6879(94)35171-6

Lerner, T. R., Lovering, A. L., Bui, N. K., Uchida, K., Aizawa, S., Vollmer, W., et al. (2012). Specialized peptidoglycan hydrolases sculpt the intra-bacterial niche of predatory Bdellovibrio and increase population fitness. PLoS Pathog. 8:e1002524. doi: 10.1371/journal.ppat.1002524

Lyczak, J. B., Cannon, C. L., and Pier, G. B. (2002). Lung infections associated with cystic fibrosis. Clin. Microbiol. Rev. 15, 194-222. doi: 10.1128/CMR.15.2.194222.2002

Mall, M., Grubb, B. R., Harkema, J. R., O’Neal, W. K., and Boucher, R. C. (2004). Increased airway epithelial $\mathrm{Na}+$ absorption produces cystic fibrosis-like lung disease in mice. Nat. Med. 10, 487-493. doi: 10.1038/nm 1028

McShane, D., Davies, J. C., Wodehouse, T., Bush, A., Geddes, D., and Alton, E. W. (2004). Normal nasal mucociliary clearance in CF children: evidence against 
a CFTR-related defect. Eur. Respir. J. 24, 95-100. doi: 10.1183/09031936.04. 00097503

Medina, A. A., Shanks, R. M., and Kadouri, D. E. (2008). Development of a novel system for isolating genes involved in predator-prey interactions using host independent derivatives of Bdellovibrio bacteriovorus 109J. BMC Microbiol. 8:33. doi: 10.1186/1471-2180-8-33

Merritt, J. H., Kadouri, D. E., and O’Toole, G. A. (2005). Growing and analyzing static biofilms. Curr. Protoc. Microbiol. Chapter 1: Unit 1B.1. doi: 10.1002/ 9780471729259.mc01b01s00

Monnappa, A. K., Dwidar, M., Seo, J. K., Hur, J. H., and Mitchell, R. J. (2014). Bdellovibrio bacteriovorus inhibits staphylococcus aureus biofilm formation and invasion into human epithelial cells. Sci. Rep. 4, 3811. doi: 10.1038/srep03811

Moore, J. E., Shaw, A., Millar, B. C., Downey, D. G., Murphy, P. G., and Elborn, J. S. (2005). Microbial ecology of the cystic fibrosis lung: does microflora type influence microbial loading? Br. J. Biomed. Sci. 62, 175-178.

Pasternak, Z., Njagi, M., Shani, Y., Chanyi, R., Rotem, O., Lurie-Weinberger, M. N., et al. (2014). In and out: an analysis of epibiotic vs periplasmic bacterial predators. ISME J. 8, 625-635. doi: 10.1038/ismej.2013.164

Rajan, S., and Saiman, L. (2002). Pulmonary infections in patients with cystic fibrosis. Semin. Respir. Infect. 17, 47-56. doi: 10.1053/srin.2002.31690

Regnis, J. A., Robinson, M., Bailey, D. L., Cook, P., Hooper, P., Chan, H. K., et al. (1994). Mucociliary clearance in patients with cystic fibrosis and in normal subjects. Am. J. Respir. Crit. Care Med. 150, 66-71. doi: 10.1164/ajrccm.150.1.8025774

Rendulic, S., Jagtap, P., Rosinus, A., Eppinger, M., Baar, C., Lanz, C., et al. (2004). A predator unmasked: life cycle of Bdellovibrio bacteriovorus from a genomic perspective. Science 303, 689-692. doi: 10.1126/science.1093027

Shimkets, L. J. (1990). Social and developmental biology of the myxobacteria. Microbiol. Rev. 54, 473-501.

Sibley, C. D., and Surette, M. G. (2011). The polymicrobial nature of airway infections in cystic fibrosis: cangene gold medal lecture. Can. J. Microbiol. 57, 69-77. doi: 10.1139/W10-105

Sockett, R. E., and Lambert, C. (2004). Bdellovibrio as therapeutic agents: a predatory renaissance? Nat. Rev. Microbiol. 2, 669-675. doi: 10.1038/nrmicro959

Starr, M. P. (1975). Bdellovibrio as symbiont; the associations of Bdellovibrios with other bacteria interpreted in terms of a generalized scheme for classifying organismic associations. Symp. Soc. Exp. Biol. 93-124.

Stolp, H., and Starr, M. P. (1963). Bdellovibrio bacteriovorus gen. Et Sp. N., a predatory, ectoparasitic, and bacteriolytic microorganism. Anton. Leeuw. 29, 217-248. doi: 10.1007/BF02046064
Tarran, R., Button, B., Picher, M., Paradiso, A. M., Ribeiro, C. M., Lazarowski, E. R., et al. (2005). Normal and cystic fibrosis airway surface liquid homeostasis. The effects of phasic shear stress and viral infections. J. Biol. Chem. 280, 35751-35759. doi: 10.1074/jbc.M505832200

Varon, M. (1981). Interaction ofBdellovibrio with Its prey in mixed microbial populations. Microb. Ecol. 7, 97-105. doi: 10.1007/BF02032491

Varon, M., Drucker, I., and Shilo, M. (1969). Early effects of Bdellovibrio infection on the syntheses of protein and RNA of host bacteria. Biochem. Biophys. Res. Commun. 37, 518-525. doi: 10.1016/0006-291X(69)90946-2

Varon, M., and Zeigler, B. P. (1978). Bacterial predator-prey interaction at low prey density. Appl. Environ. Microbiol. 36, 11-17.

Yair, S., Yaacov, D., Susan, K., and Jurkevitch, E. (2003). Small eats big: ecology and diversity of Bdellovibrio and like organisms, and their dynamics in predator-prey interactions. Agronomie 23, 433-439. doi: 10.1051/agro: 2003026

Zielenski, J., and Tsui, L. C. (1995). Cystic fibrosis: genotypic and phenotypic variations. Annu. Rev. Genet. 29, 777-807. doi: 10.1146/annurev.ge.29.120195. 004021

Conflict of Interest Statement: The authors declare that the research was conducted in the absence of any commercial or financial relationships that could be construed as a potential conflict of interest.

Received: 19 April 2014; accepted: 22 May 2014; published online: 05 June 2014.

Citation: Iebba V, Totino V, Santangelo F, Gagliardi A, Ciotoli L, Virga A, Ambrosi C, Pompili M, De Biase RV, Selan L, Artini M, Pantanella F, Mura F, Passariello C, Nicoletti M, Nencioni L, Trancassini M, Quattrucci S and Schippa $S$ (2014) Bdellovibrio bacteriovorus directly attacks Pseudomonas aeruginosa and Staphylococcus aureus Cystic fibrosis isolates. Front. Microbiol. 5:280. doi: 10.3389/ fmicb.2014.00280

This article was submitted to Infectious Diseases, a section of the journal Frontiers in Microbiology.

Copyright (c) 2014 Iebba, Totino, Santangelo, Gagliardi, Ciotoli, Virga, Ambrosi, Pompili, De Biase, Selan, Artini, Pantanella, Mura, Passariello, Nicoletti, Nencioni, Trancassini, Quattrucci and Schippa. This is an open-access article distributed under the terms of the Creative Commons Attribution License (CC BY). The use, distribution or reproduction in other forums is permitted, provided the original author(s) or licensor are credited and that the original publication in this journal is cited, in accordance with accepted academic practice. No use, distribution or reproduction is permitted which does not comply with these terms. 